\title{
An Effective Paradigm on Self-Regulating Cautious Strategy
}

\author{
Jaipriya.S, Malathy.S, Anitha.G, Renjitha.R
}

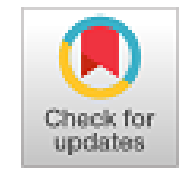

\begin{abstract}
The number of accidents in the world is increasing day by day and most of these accidents are effectuated due to Driving While Intoxicated (DWI). Therefore, since the death due to the Drunken-Driving or Driving Under the Influence (DUI) of alcohol has assumed proportion larger(60\%) than one can visualize. In order to combat such life-risking psroblems, we have designed a mock-up. This safety serious system is actualized using ARDUINO and the main unit of this project is alcohol detecting sensor. Here alcohol sensor(MQ3) is used in a steering wheel and also in the passenger seat to sense the alcohol molecules present inside the vehicle. When sensor equipped in a steering wheel senses the alcohol content (i.e)., when the level of alcohol of driver crosses a permissible limit, fails the attempt of the driver to start the engine irrespective of the passenger. To thwart the accidents due to immediate engine failure, a timer is proposed in the exemplary. This framework is also embodied with widely used GSM MODEM and it will automatically send the distress message to the owner of the vehicle or to the family member.
\end{abstract}

Keywords: Alcohol sensor (MQ3), Short Messaging Service (SMS), Safety Serious System (SSS), Global System for Mobile Communication (GSM), Timer, Automatic Engine Locking.

\section{INTRODUCTION}

Drunk driving is a major life-threatening problem around the world. In an analysis, over 10,000 traffic fatalities were directly associated with drivers who had Blood Alcohol Content (BAC) or Blood Alcohol Concentration above $0.08 \mathrm{mg} / \mathrm{dl}$. The legal limit of BAC is $0.05 \%$ or $5 \mathrm{mg}$ per 100 $\mathrm{ml}$ or $1 \mathrm{dl}$. Drivers demand complete attention, spontaneous action, self-control, and quick decision-making abilities to avoid any unanticipated incidents while driving a vehicle. But drunken drivers will not be in a stable condition.

Revised Manuscript Received on October 30, 2019.

* Correspondence Author

S.Jaipriya*, Assistant professor, Department of Electronics and Communication Engineering, Sri Krishna College of Technology, Tamil Nadu, India.

Dr. Malathy S, Professor in Sri Krishna College of Technology, Coimbatore, India PhD Wireless communication from Anna University, Tamil Nadu, India.

G.Anitha B.E, Department of Electronics and Communication Engineering, MEPCO Schlenk Engineering College, Tamil Nadu, India.

Renjitha R, BE degree from CMS College Of Engineering And Technology, Department of Electronics and Communication Engineering, Sri Krishna College of Technology, Tamil Nadu, India.

(C) The Authors. Published by Blue Eyes Intelligence Engineering and Sciences Publication (BEIESP). This is an open access article under the CC BY-NC-ND license (http://creativecommons.org/licenses/by-nc-nd/4.0/)
When BAC crosses $0.08 \%$, alcohol in the blood seizes the human brain working and it results in a lack of concentration, difficulties in controlling the speed, drowsiness, slow reaction time, loss of self-control. [10] States that the above mentioned factors result in rash driving. Hence it is an inconvenience for the other road users and a question of life. Body Area Network (BAN) an under-developing technology, which can be able to provide mobility for person with Wearable or Implantable devices in and around the body, who are wandering within the coverage region of monitoring system. BAN or WBAN plays a pivotal role in Human Healthcare. By integrating the concepts of WBAN and WSN, the proposed automotive alcohol detection system caters an efficacious solution for the safety of the people inside the car, pedestrians and other motorists. This framework detects the alcohol molecules in human breath, provides the corresponding analog resistive output to the arduino to control the vehicle ignition with low power consumption. The system encompassed with the timer to avert immediate engine failure after alcohol detected inside the vehicle. To report accidents occurring in real time the alert system is implemented by deploying GSM. This system also enables the inter-city transport companies to effectively track their vehicles.

\section{LITERATURE SURVEY}

According to the World Health Organization (WHO) Report on September 2018: The deaths that occur on India's roads is almost 1 lakh, which are indirectly related to driving vehicles under the influence of alcohol. In [3], reveals about aspproximately 336 people/day die in Road accident, but as of WHO report 2018, the number increased to 400 deaths/day which impelling India to take car safety seriously. Model [6] admits around million children killed due to over-speeding. For a 1\% increase in mean speed culminates in a $4 \%$ increase in the road fatalities. To curtail accident rate due to over speeding, model [5] uses GSM and GPS to send the message when speed of the vehicle and amount of tilting exceeds. System [2] exemplifies the traffic mechanism for speed control, SONAR in this system supports to determine the distance of surrounding vehicles. Once when an obstacle is captured, vehicle stopped. 


\section{An Effective Paradigm On Self-Regulating Cautious Strategy}

Psychological state of the driver such as Drowsiness \& Distraction acting as a root to endorse night accidents. More than $80 \%$ of accidents due to drunken driving accidents take place between 1 am to 4 am. To safeguard the drowsiness and drunk drivers, [8] embodies Eye-blink sensors to find the driver drowsiness and Alcohol sensor for detecting the drunken state of the driver. It adopts GSM to send an SMS when the driver is caught in inebriated condition. It also focuses on obstacle detection mechanism using proximity sensor. In [12], depending on the alcohol concentration and Eye blinking rate, Speed of the vehicle varies. This system triggers alarm, activation of auto pilot. Smart-Helmet mechanism for Two-Wheeler Accident prevention elucidated in [7], which senses alcohol content and sends data to Smartphone via Bluetooth Module when an Accident is detected. Using Vibration Sensor, [9] reduces the action time after Accident. This clearly depicts that Driving While Intoxicated (DWI) and Rash Driving are the major sources of Road accidents across the world. These accidents will also have adverse impacts on Pedestrians, Elderly Citizens and School children who are crossing the road at that time. Survivors from these Road Accidents will lead a Traumatized life.

\section{SSS MODEL}

In an existing system, automatic engine locking process was done in an unprotected way, i.e when the alcohol is detected by the sensor the motor is turned off immediately. This immediate engine breakdown may cause unexpected accidents. Thus in the proposed model, this limitation is overcome by using a timer system. A block diagram of the SSS (Safety Serious System) Model is represented in Fig.3. This system is divided into three sections:

$$
\begin{array}{ll}
\text { - } & \text { Sensing } \\
\text { - } & \text { Processing } \\
\text { Actuating network }
\end{array}
$$

Sensing part consists of Infrared (IR) and Alcohol (MQ3) Sensor. Infrared Sensor in the system is used for efficacious power usage. It initiates the whole process only when a person is detected inside the vehicle. The motor will be ON only when a non-alcoholic breath is detected. Alcohol Sensor continuously monitors the driver's breath and produces an analog resistive output. Processing part has a Microcontroller. Using MQ3 Sensor, microcontroller sways the whole system. Arduino which is the heart of the system reads the data from MQ3 Sensor. Analog to Digital Converter (ADC) in Arduino converts the analog data from the sensor to corresponding digital data. In response to the detected alcohol percentage, Microcontroller controls the actuating element (DC Motor) and sends a warning message to the concerned person.

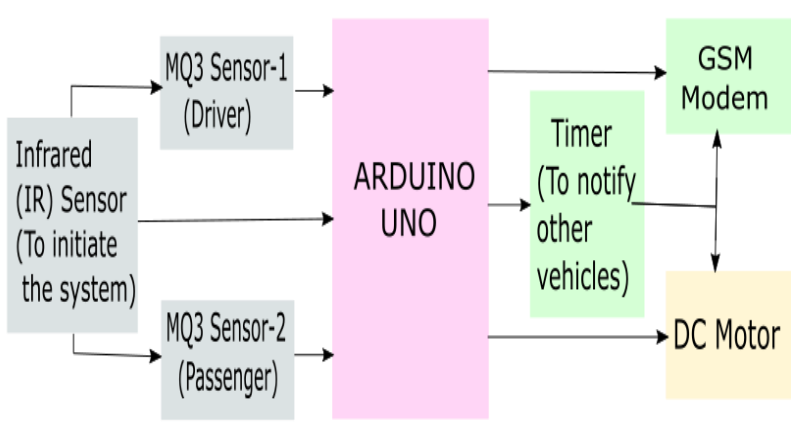

Fig. 1. SSS Model Block Diagram

Consider a scenario of a car equipped with SSS model as shown in Fig 4 by the owner of the vehicle. When the driver gets inside the car the SSS model activates in a jiffy. The model activation is done by the IR sensor used in the circuit. The system will be in 'ON' state only when the IR sensor output is high (i.e. $I R=1$ ). Effectively saying when the person sits inside the vehicle is sensed by the IR sensor and sends the output to the controller to initiate the system, until the circuit remains in 'OFF' state or in 'Sleep' mode.

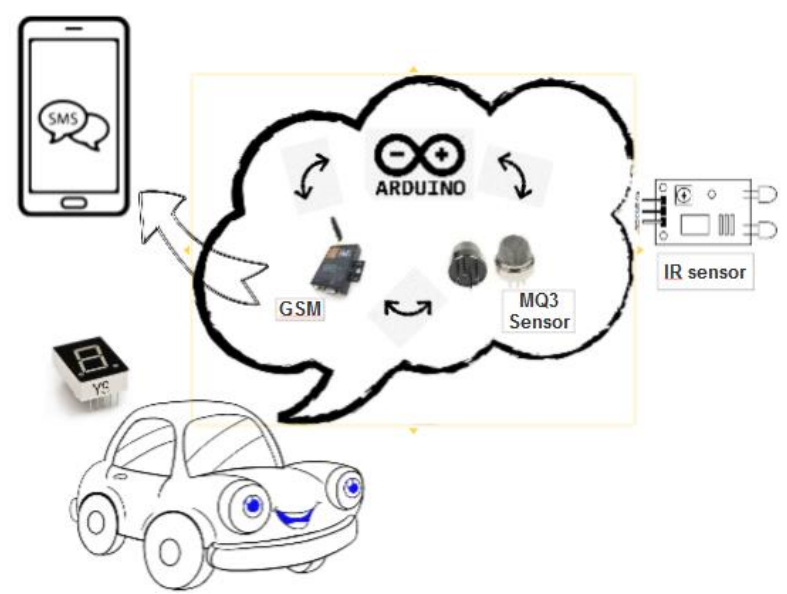

Fig. 2. SSS Equipped Car

Once the system turns 'ON' state, the onboard alcohol sensor will detect the alcohol content in the driver's breath and sent its value to the controller board (Arduino). The purpose of the sensor module is to provide a technique to compare alcohol source with a reference or an acceptable level and when the source exaggerates, it is capable to set an alarm limit. It acts similar to a common breathalyzer circuit. Since the sensor has gas sensitive material to sense alcohol, it has high sensitivity to small value. From the MQ3 sensitivity graph shown in Fig 5, its sensitivity towards hexane, $\mathrm{CH} 4$, and $\mathrm{CO}$ is less when compared to alcohol which is very high. To obtain a meticulous measurement, the sensor's alarm circuit has to be fixed by considering the temperature and humidity influence. 


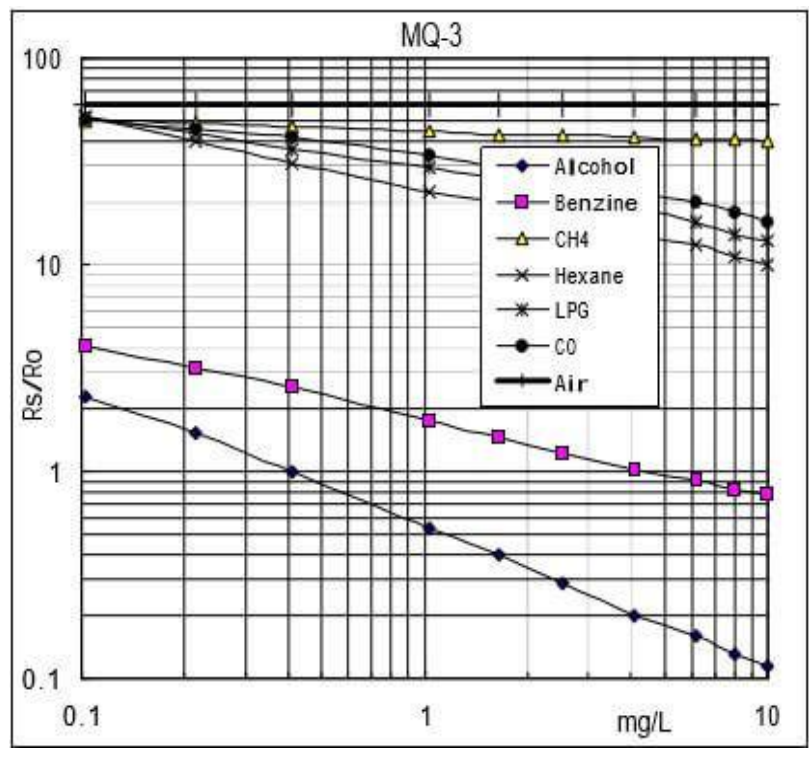

Fig. 3. MQ3 Sensor sensitivity graph

As the result of alcohol detection the controlling process is done by the core part of this prototype (Arduino board). This board mastery the engine and turns it down as soon as the alcohol is detected. The next stage before the engine fiasco is the notification provided by the timer to alert other road users. It is a specialized type of clock which is used to sync operation time with a system clock. With extension, the alert note is sent to the vehicle holder by the low power GSM modem which uses a protocol based on the Hayes AT-Command set as shown in Fig 6 to setup and control the transmission and reception of data.

Table 1. AT command

\begin{tabular}{|l|l|}
\hline Command & Description \\
\hline AT & $\begin{array}{l}\text { Check if serial interface and GSM } \\
\text { modem is working }\end{array}$ \\
\hline ATEO & $\begin{array}{l}\text { Turn echo off, less traffic on serial } \\
\text { line }\end{array}$ \\
\hline AT+CNMI & Displays new incoming SMS \\
\hline AT+CPMS & Selection of SMS memory \\
\hline AT + CMGF & $\begin{array}{l}\text { SMS string format, how they are } \\
\text { compressed }\end{array}$ \\
\hline AT + CMGR & $\begin{array}{l}\text { Read new message from a given } \\
\text { memory location }\end{array}$ \\
\hline AT+CMGS & Send message to a given recipient \\
\hline AT +CMGD & Delete a message \\
\hline
\end{tabular}

\section{PROCESS CONTROL}

Whenever a person sits inside the vehicle, IR sensor initiates the system. For effectual power consumption, IR sensor is used over here.

\subsection{Driver consumed Alcohol:}

The MQ3 Sensor in the steering wheel checks whether the person consumed alcohol or not. If a drunken driver sits in the driver seat, it works on two cases:
1. When the vehicle is not moving, then the alcohol sensor detects the alcohol content based on the breath of the driver and it fails the foray of the driver to start the engine.

2. If the driver consumes alcohol during driving, then the MQ3 sensor sends a digital HIGH output to ARDUINO. Then it turns ON the Timer to notify other vehicles such that the vehicle is going to stop instantly and this prevents the accidents that will occur due to immediate engine failure. Once the counter value reaches zero, the speed of the vehicle gradually diminishes.

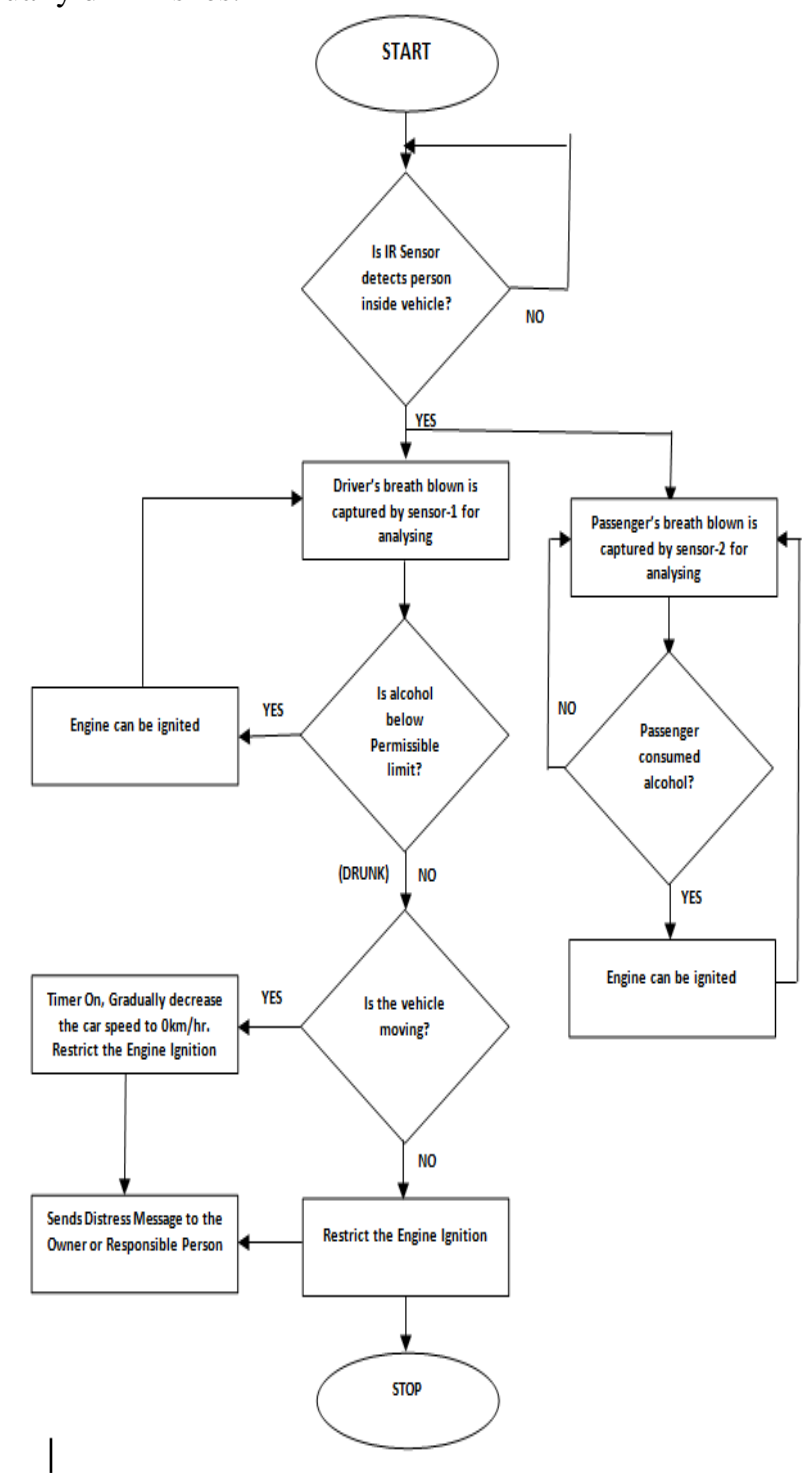

\subsection{Passenger consumed Alcohol:}

To avoid interrupting the system with alcohol molecules from the breath of the passenger, here MQ3 Sensor is also placed in the passenger seat. Hence this system works based on the alcohol consumption of driver irrespective of the passenger.

\section{RESULTS AND DISCUSSION}




\section{An Effective Paradigm On Self-Regulating Cautious Strategy}

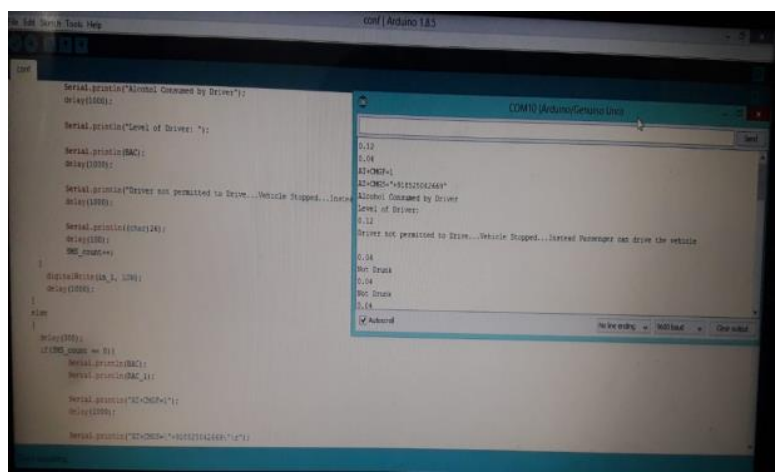

Fig. 5. Software simulation window

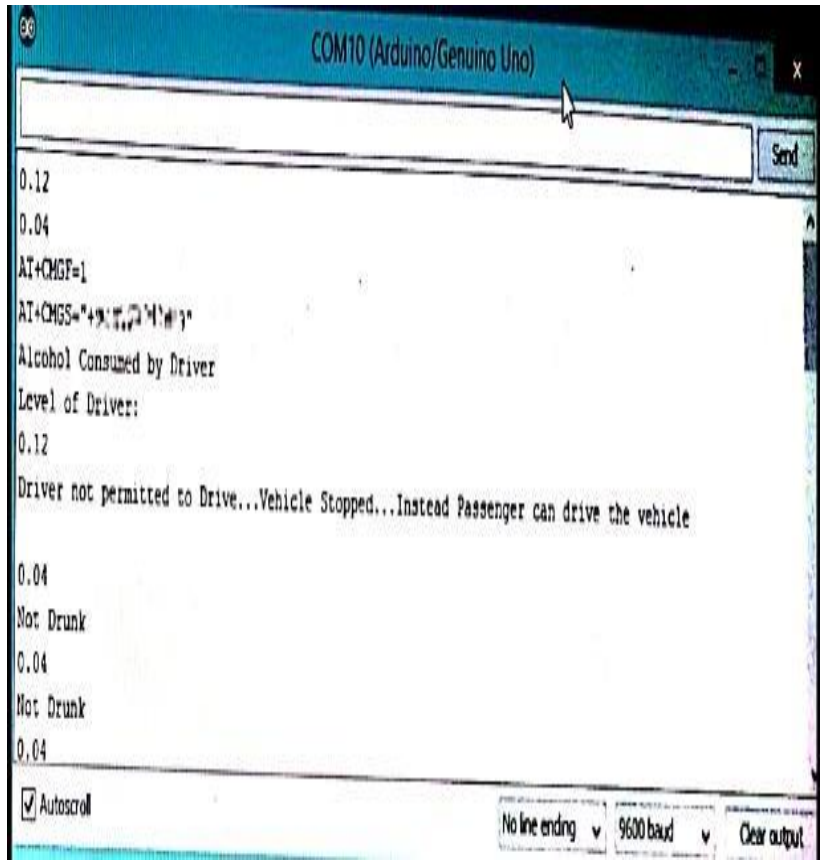

Fig. 6. Safety Serious System output window

\section{Alcohol Consumed by Driver \\ Level of Driver: \\ 0.12 \\ Driver not permitted to Drive... \\ Vehicle Stopped...Instead \\ Passenger can drive the vehicle}

\section{Alcohol Consumed by Driver Level of Driver:}

0.12

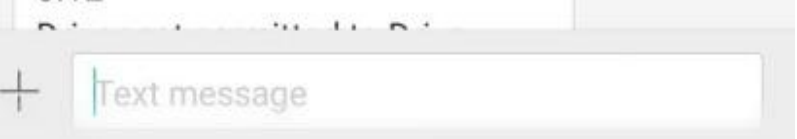

Fig. 7. Alert note from GSM

From Fig 5 it is absorbed that MQ3 Sensor is Heat-Driven Device. It takes some time to sense precisely. The moment the sensor detects the alcohol molecules, it locks the ignition system and sends a distress message to the concerned persons. From Fig 6 it is inferred that, when the alcohol is detected, an acknowledgment about the alcohol level of the driver and the vehicle condition is sent by the Arduino. Fig 7 ensures the successful conveyance of SMS to the registered number of the authorized person from the system modem. The driver does not consent to Drunk Driving or Driving Under the Influence (DUI) of Alcohol.

\section{CONCLUSION}

Fire and ice can still make a pair, but drinking and riding can never get assort. When it goes together, the result will be incorrigible. Hence the SS system helps to find and preclude accidents before it happens. This device provides well-advanced facilities and has a great pertinence in today's world as it can curtail alcohol-related road fatalities and mortalities..

\section{FUTURE WORK}

The paper can be extended to an improved version for obviating drunken drivers from getting on the road with a new concept using various digitized alcohol detection sensors. In future instead of using MQ3 sensor, wearable sweat sensors can be used to check the alcohol content level in the blood from the sweat. Using sweat sensor will be more accurate when compared to MQ3 sensor. This can be accompanied by an RFID sensor to prevent the fraudulent. This system can be enhanced using Accelerometer to identify Potholes in Roads. One can also encompass GPS Module ${ }^{[2][3]}$ that might provide additional functionality to track the vehicle efficaciously. Hence a system with wearable sweat sensor supported with identification mechanism for authorized and unauthorized car owner along with location tracking can cumulatively contribute to absolute safe driving.

\section{REFERENCES}

1. Shahad Al-Youif., Musab A. M. Ali, M. N. Mohammed, "Alcohol Detection For Car Locking System”, C2018 IEEE

2. Jaipriya S, Malathy S, Srinivasan K, Priyanka B Charliene Karunya L“A Framework for Energy Optimization in Wireless Sensor Nodes at Ad-Hoc network", 2nd International Conference on I-SMAC (IoT in Social, Mobile, Analytics and Cloud) (I-SMAC),2018 IEEE

3. K Divya, S Jaipriya, G Anitha, S Malathy, R Maheswar "An Energy Efficient Technique for Time Sensitive Application using MC-WSN" 2018 2nd International Conference on Inventive Systems and Control (ICISC),2018 IEEE

4. Taieba Taher, R.U.Ahmed, M.A.Haider, Swapnil.Das, M.N.Yasmin, Nurasdul Mamun, “Accident Prevention Smart Zone Sensing System”, 2017 IEEE Region 10 Humanitarian Technology Conference (R10-HTC) 21 - 23 Dec 2017, Dhaka, Bangladesh, (C)2017 IEEE.

5. Pughazendi.N, Sathishkumar.R, Balaji.S, Sathyavenkateshwaren.S, Subash Chander.S, Surendar.V, "Heart Attack and Alcohol Detection Sensor Monitoring in Smart Transportation System using Internet of Things", International Conference on Energy, Communication, Data Analytics and Soft Computing (ICECDS-2017), (C2017 IEEE

Published By: 
6. D.Selvathi, P.Pavithra, T.Preethi, "Intelligent Transportation System for Accident Prevention and Detection", International Conference on Intelligent Computing and Control Systems (ICICCS), (C2017 IEEE

7. Md.Sadad Mahamud, Maliha Monsur, Md.Saniat Rahman Zishan. "An Arduino Based Accident Prevention And Identification System For Vehicles”, 2017 IEEE Region 10 Humanitarian Technology Conference (R10-HTC) 21 - 23 Dec 2017, Dhaka, Bangladesh, C2017 IEEE

8. Seelam.K, Lakshmi.C.J, "An Arduino based embedded system in passenger car for road safety", 2017 International Conference on Inventive Communication and Computational Technologies (ICICCT), (C)2017 IEEE

9. Ms.M.Malathi, Ms.R.Sujitha, Ms.M.R.Revathy, "Alcohol Detection and Seat Belt Control System using Arduino”, 2017 International Conference on Innovations in information Embedded and Communication Systems (ICIIECS), C2017 IEEE

10. Das.A, Ray.A, Ghosh.A, Bhattacharyya.S, Mukherjee.D, Rana.T. K, "Vehicle accident prevent cum location monitoring system", 2017 8th Annual Industrial Automation and Electromechanical Engineering Conference (IEMECON), C2017 IEEE

11. Tushara.D.B, Vardhini.P.A.H, "Wireless vehicle alert and collision prevention system design using Atmel microcontroller" 2016 International Conference on Electrical, Electronics, and Optimization Techniques (ICEEOT), C2016 IEEE

12. Sinan Kaplan, Mehmet Amac Guvensan, Member, IEEE, Ali Gokhan Yavuz, and Yasin Karalurt, "Driver Behavior Analysis for Safe Driving: A Survey", IEEE TRANSACTIONS ON INTELLIGENT TRANSPORTATION SYSTEMS, VOL. 16, NO. 6, DECEMBER 2015, (C)2015 IEEE

13. Raja Raghavan.M, Bhuvaneswari.N.S, "Intelligent safety and security systems in automobiles", 2015 IEEE Technological Innovation in ICT for Agriculture and Rural Development (TIAR), C2015 IEEE

14. Sahabiswas.S, Saha.S, Mitra.P, Chatterjee.R, Ray.R, Saha.P, Biswas.B.A, "Drunken driving detection and prevention models using Internet of Things" 2016 IEEE 7th Annual Information Technology, Electronics and Mobile Communication Conference (IEMCON), (C)2016 IEEE

\section{AUTHORS PROFILE}

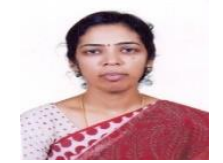

S.Jaipriya is Assistant professor in Department of Electronics and Communication Engineering at Sri Krishna College of Technology, who has completed her Master's in Applied Electronics at Kumaraguru college of Technology. Her key area of research is Networking, Digital Image Processing, and Energy Optimization in Sensor Nodes. She has published 2 papers in Scopus indexed journal and published 2 patents in the domain Wireless Sensor Network

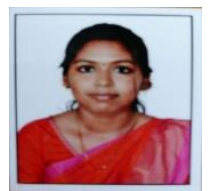

Dr.Malathy S, Professor in Sri Krishna College of Technology, Coimbatore, India has received her $\mathrm{PhD}$ in Wireless communication from Anna University. She has been awarded as Best Faculty in her career. Her research area extends in Wireless Sensor Networks, Body Are Networks and Antenna Designs, She has published more than 25 papers in various International Journals and published two Indian Patents.

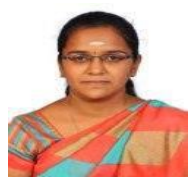

G.Anitha received B.E degree from the Department of Electronics and Communication Engineering, MEPCO Schlenk Engineering College, Sivakasi, in 2001 and M.E (Applied Electronics) degree from the Department of Electronics and Communication Engineering, SSN College of Engineering, Chennai, in 2007. She is an Assistant Professor in Department of Electronics and Communication Engineering, Sri Krishna College of Technology, Coimbatore, India. She has authored over 12 International Conference/Journal papers in Sensor networks. Her research interest includes Computer Networks, Wireless Sensor Networks. She is a member of ISTE and a reviewer of Wireless Networks Journal.

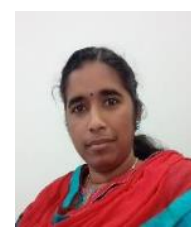

Renjitha $\mathbf{R}$ received her BE degree from CMS College Of Engineering And Technology in 2017,Completed her ME in Electronics And Communication, specialized in Communication Systems from Sri Krishna College O Engineering And Technology in 2017, recently joined as Assistant professor in Sri Krishna College Of Technology. 